\title{
A smart gas leakage monitoring system for use in hospitals
}

\author{
Nadia Mahmood Hussien' ${ }^{1}$, Yasmin Makki Mohialden², Nada Thanoon Ahmed ${ }^{3}$, \\ Mostafa Abdulghafoor Mohammed ${ }^{4}$, Tole Sutikno ${ }^{5}$ \\ ${ }^{1,2,3}$ Computer Science Department, Collage of Science, Mustansiriyah University, Iraq \\ ${ }^{4}$ Imam Aadham University College, Iraq \\ ${ }^{5}$ Department of Electrical Engineering, Universitas Ahmad Dahlan, Indonesia
}

\begin{tabular}{l}
\hline Article Info \\
\hline Article history: \\
Received Jan 13, 2020 \\
Revised Mar 15, 2020 \\
Accepted Mar 22, 2020 \\
\hline Keywords: \\
Arduino \\
Gas leaking detector \\
GSM \\
MQ2 sensor \\
MQ9 sensor \\
Security system \\
SMS \\
\hline
\end{tabular}

\begin{abstract}
A gas leaks lead to personal and financial damage. Much effort has been dedicated to preventing such leaks and developing reliable techniques for leak detection and leakage localization using sensors. These sensors usually sound an alarm after detecting a dangerous gas in its vicinity. This paper describes a system for detecting a gas leakage from cylinders which notifies the user via the GSM network. The system consists of an LPG gas leakage detector which sends a warning signal to Arduino Uno Microcontroller. The system uses the GSM network to send notifications, a liquid crystal display (LCD) monitor to display the warning message and buzzer to sound the alert.
\end{abstract}

Copyright $\odot 2020$ Institute of Advanced Engineering and Science. All rights reserved.

\section{Corresponding Author:}

Yasmin Makki Mohialden,

Computer Science Department, Collage of Science,

Mustansiriyah University, Baghdad, Iraq.

Email: ymmiraq2009@uomustansiriyah.edu.iq

\section{INTRODUCTION}

The The use of gas for medical purposes is often vital, therefore the gas cylinder warehouse is considered an integral part of any hospital. Hospitals usually have even an extensive gas supply network that deliver a number of different types of gases to vaious locations inside the hospital such as patient and operating rooms [1, 2]. For safety reasons, hospitals must have a smart gas leakage monitoring system. This system becomes even more useful and effective when it is linked to global system for mobile communication (GSM). Mohammed et al [3-6] that way, the system will be capable of sending a warning message to the hospital's saftey personals in case the system detects any gas leakage [7].

Hospitals, clinic, and community health institutions will be completely distinct from different work ambiences [6, 8]. Tending frameworks are complicated and there exist several belongings that must be comprehended and varieties of hospital systems, patient care, insurance, tending suppliers, and legal problems [9-11]. There exists a good sort of health framework throughout the universe, conjointly since several histories alongside healthcare frameworks as there exist several nations. Fundamentally, country should style and frame health systems in connection with the wants and resources, through shared components in just about all health frameworks are basically healthcare along with the health aspects $[4,12,13]$. In various countries, health system coming up with is dispersed among market participants. In many cases, there's a united endeavor among governments, charities, trade unions, spiritual establishments, or different coordinated bodies to afford planned healthcare offerings aimed at the populations they focus on. On the contrary, healthcare has been represented in the form of a typical biological process instead of revolutionary [14-16]. 
This paper describes such a system that uses Arduino to send a notification to the user's mobile. The paper is structured as follows: Section 1 introduction, Section 2 describes related work, Section 3 the proposed system, Section 4 hardware components, Section 5 software components, Section 6 results and discussion section and finally Section 7 conclusion.

\section{RELATED WORK}

Simbeye et al [7] describes agas leakage detection system for home users. The system includes a liquefied petroleum gas (LPG) sensor for detecting gas leak linked to a microcontroller. This microcontroller gives an alert whenever a gas leakage is detected. It even displays a warning information using liquid crystal display (LCD), and sends a modifying SMS to the user for notification. The system turn off electric power using a magnetic relay.

Fraiwan et al [17] outlines a wireless system for detection of gas leakage forhome users. The system consists of two main elements: the first checks if the concentration of gases exceedes a predetermined threshold. Once such change happens, it will activate an audiovisual alarm and sends a signal to a receiver module that acts as a mobile alarm device, thus facilitating mobility within the house site.

Ishak et al [18] discussed a wireless module to detect a gas leakage, the module is placed in the house for detecting LPG leakage. The module reads the gas sensor and detect whether the gas concentration has exceeded a specified range. When this happenes, the alert will be activated and it will send a warning SMS to a specific recipient using a GSM module.

Azibek [19] studied smart home health system for monitoring the health of an elderly person. If abnormal health rate vitals are detected, it alert medical personal by sending an email. This smart home health system also contains gas sensors for detecting fire occurrence and a camera for detecting thieves. The system is used by elderly people suffering of amnesia/memory loss by sending reminding notifications about daily routine tasks.

\section{PROPOSED SYSTEM}

The smart system is intended for use at hospitals. When a sudden leakage happens, the gas sensor sends a signal to the microcontroller. The controller processes a signal and send notification to other external devices attached such as LCD, buzzer and an GSM module which previously stored phone numbers of the persons that are responsible on fighting fires in the hospital, this alarm will send it repeatedly until an accepting reply message received.

A smart system will contain necessary sensors for detecting gas leakage. It scans for gas leakage and show the result in the LCD. When the sensors find any gas leakage in a room or where the devices are installed, it immediately sends a notification by GSM network, there will be an automatic messaging generating operation. The gas sensors keep on scanning for gas, it detects the leak depending on the predefine threshold. The system works independently on human enters, also it works dependably by the human or the responsible operator presses push button switch, when any leak occurs. The block diagram of whole system is shown bellow in Figure 1.

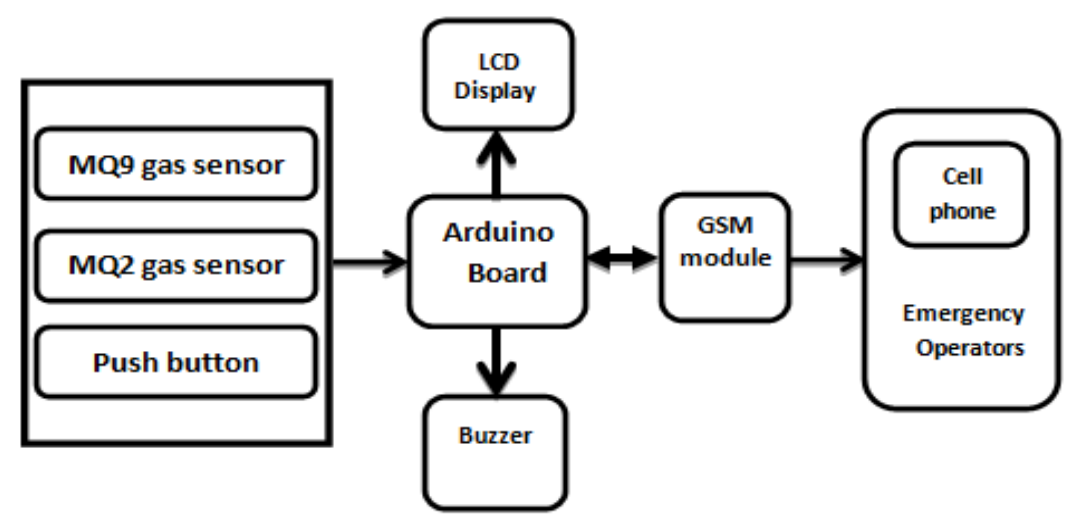

Figure 1. Block diagram of the proposed system 


\section{HARDWARE COMPONENTS}

The prototype of the propsed system is shown in Figure 2. The system which includes of:

A. Arduino microcontroller board

It is based on the ATmega328P which has 14 digital input/output pins (of which six is used as PWM outputs), six analogue inputs, a $16 \mathrm{MHz}$ ceramic resonator (CSTCE16M0V53-R0), a USB connection, a power jack, an ICSP header and a reset button. It connected to a computer with a USB cable or power it with an AC-to-DC adapter or battery to get started. Arduino Uno R3 type used in this research [20].

B. Gas sensors

Two types of MQ sensors are used in this system, these sensors use a small heater found inside it with an electrochemical sensor that used to change the sensitivity of gasses. When the sensor is working in clean air, it's conductivity of value is lower and it is increasing with gas concentration rising. Table 1 illustrates these sensors with its target gas. sensors with the target gas [21].

C. Global System for Mobile Communication (GSM) Module

GSM module is a chip or circuit that will be used to establish communication between a mobile device or a computing machine and a GSM system for sending and receiving information. Also, it is connected to the internet [22].

D. Pushbutton switch

Pushbutton switch used as a personal notification in this system, when any abnormal state (gas leak) occurs. It activates by pressing to let the signal pass to Arduino.

E. Liquid crystal display (LCD)

LCD is a flat panel display technology which used commonly in computer monitors and as screens for mobile devices, such as laptops, tablets, and smart phones [23], It is used in this research to visualize the values of the sensors and notification message.

F. Buzzer module

Buzzer module consists of an active piezoelectric buzzer. The sound of buzzer is controlled by Arduino which activates it according to the signal that pass to buzzer. The module generates a sound when signal is high [24].

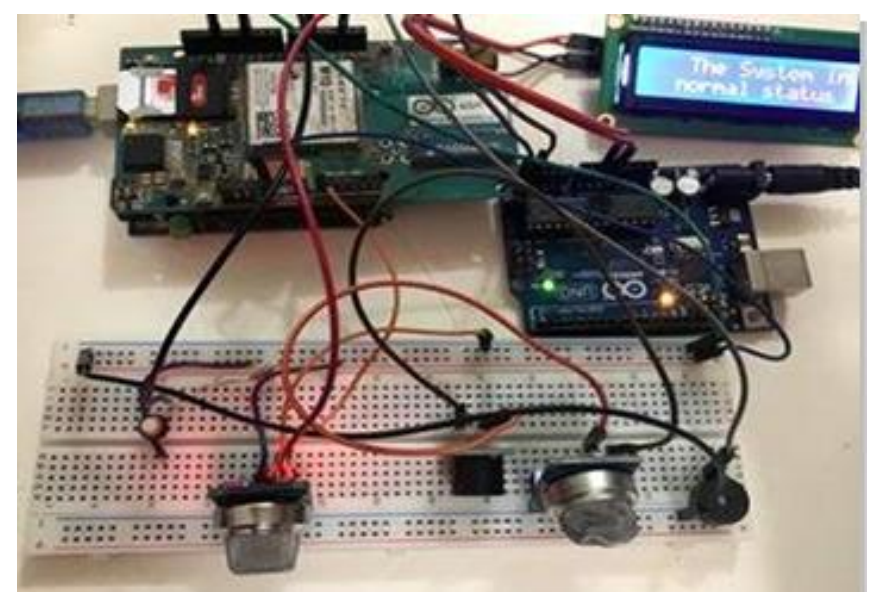

Figure 1. The prototype of whole system

Table 1. The module of sensor and its target

\begin{tabular}{|c|c|}
\hline Model & Target Gas \\
\hline MQ2 & Sensitive for Methane, Butane, LPG, smoke \\
\hline MQ9 & $\begin{array}{l}\text { Sensitive for Carbon Monoxide, flammable gasses (Hydrogen, Butane, Ethylene, Methane, acetylene, ammonia, } \\
\text { ethane, propane and silane) }\end{array}$ \\
\hline
\end{tabular}

\section{SOFTWARE COMPONENTS}

Arduino UNO software: It is programmed using the open-source Arduino Software (IDE) version ARDUINO 1.8.12, it is used to write code and upload it to the board. The software runs on Windows, Mac OS X, and Linux. The environment is written in Java and based on Processing and other open-source software [7]. 


\section{THE SOFTWARE DESIGN}

Use case diagram describes the functionality of the system. The proposed smart system suggests two actors, smart system, and emergency operator. An actor is a role that a user or some other system plays when interacting with the system [25]. Figure 3 illustrative the use case diagram of the whole system.

\section{Gas detection system}

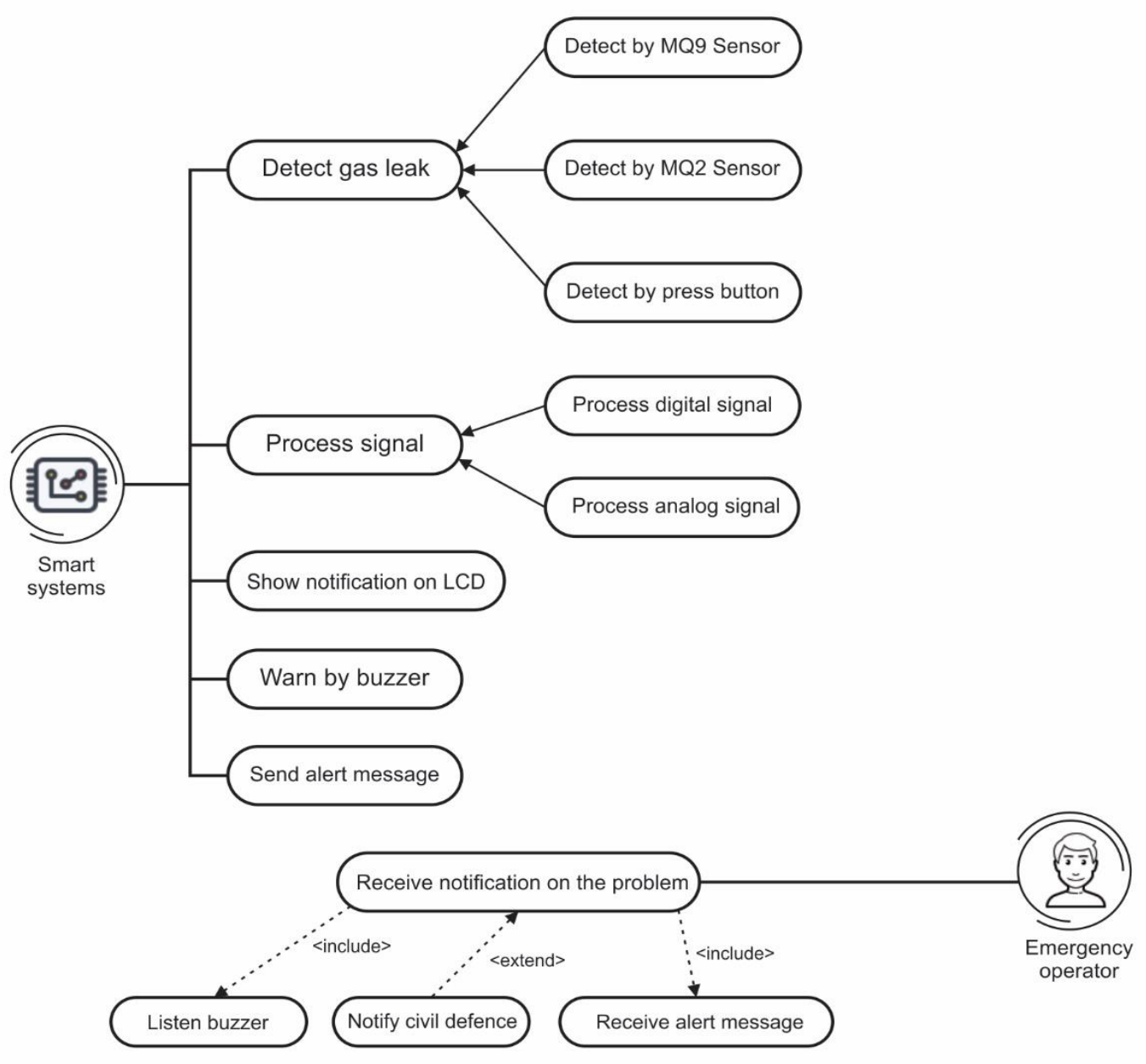

Figure 3. The Use case diagram of the system

These use cases are:

A. Detect gas leak

This use case initiated by smart system actor, it has a generalization relation (is- a) with three sub use cases (Detect by MQ9, Detect by MQ2, Detect by push button). The system detects the gas leak by mq9, mq2 sensors and pushbutton switch.

B. Process signal

This use case initiated by smart system actor; it has a generalization relation (is- a) with two sub use cases. The system processes two types of signals (digital, analog), which receive and/or sent.

C. Show notification on LCD

This use case initiated by smart system actor; the system displays the notification on status of the sensor.

D. Warn by buzzer

This use case initiated by smart system actor; the system sounds the buzzer when any leak of gas occurs.

E. Send alert message

This use case initiated by smart system actor. When any gas leak occurs, the system can send the alert message over GSM network to emergency operator. 
F. Receive notification

This use case initiated by emergency operator actor. The emergency operator receives the notification on the problem. This uses case has two inclusions relations with two use case (listen buzzer, send alert message), also it has extension relation with (notify civil defense) use case. This relation is used to make optional interactions explicit or to handle exceptional cases which means if the emergency operator does not solve the problem of gas leaking, it calls the civil defense.

\section{RESULTS AND DISCUSSION}

The detect gas leak system requires 5-volt input voltage to function. The system is plugged with MQ9, MQ 2, Pushbutton switch and GSM module. All modules function distinctively and produce their own outputs. The system senses the different gases, Carbon Mono-Oxide (CO), Alcohol, Smoke, CO2, Hydrogen $(\mathrm{H} 2)$, Butane $(\mathrm{C} 4 \mathrm{H} 10)$, Ethylene $(\mathrm{C} 2 \mathrm{H} 4)$, Methane $(\mathrm{CH} 4)$, Acetylene $(\mathrm{C} 2 \mathrm{H} 2)$, Ammonia $(\mathrm{NH} 3)$, Ethane (C2H6), Propane (C3H8), and Silane (SIH4) in an environment.

Once the system is powered on, the detect devices will be turned on and it start generating data. This data will be sent to three mediums, the com port, LCD and the GSM module. The output seen from a computer screen, LCD and cell phone is shown below in Figures 4, 5, 6, and 7.

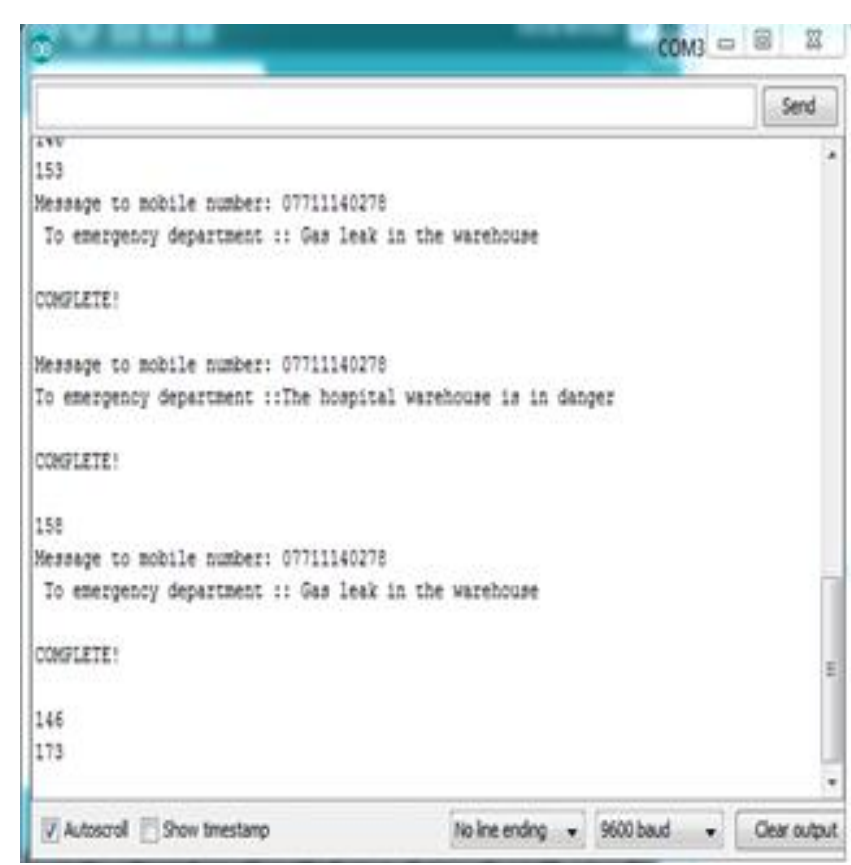

Figure 4. Sample output seen on computer

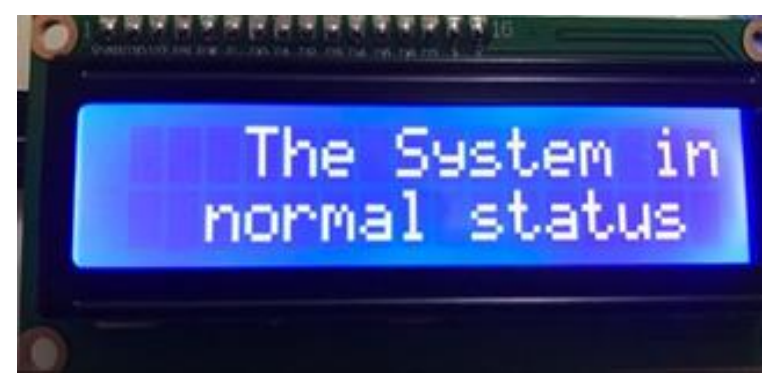

Figure 6. The output of LCD during normal status of system

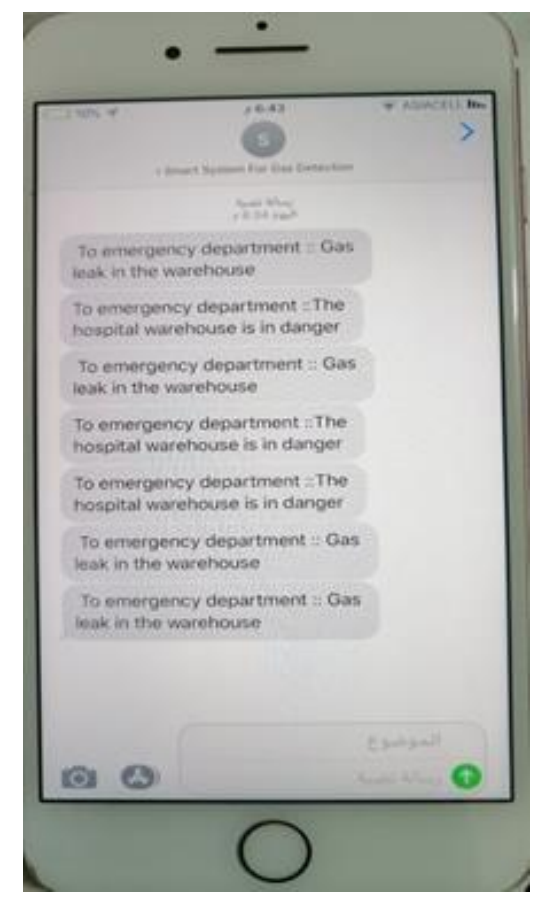

Figure 5. Alert message sends to emergency operator

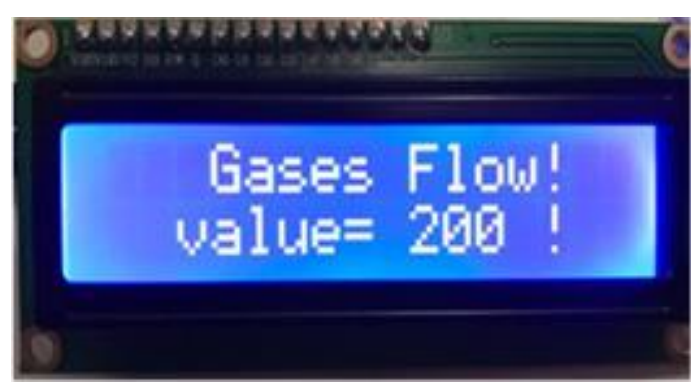

Figure 7. The output of LCD during gases leak 
There are two messages will be sent to enable the emergency operator differentiated between the status of sensors and status of push button switch, these are:

a) The first is (to emergency department: Gas leak in the warehouse) which sent when the sensors sense the gases leak.

b) The second is (to emergency department: The hospital warehouse is in danger) which sent when the push button presses.

The system can be placed anywhere and data can be taken from anywhere

\section{CONCLUSION}

Generally, the gaswarehouses is one of important parts in a hospital. To ensure safe operation, design and implementation of a smart system to detect and inform safteey personals about any gas leakagewithin the minimum possible time. This Smart gas detection system is based on Arduino microcontroller board, All sensors are connected to the microcontroller board. The gathered signals are processed to generate an alert message throught the GSM network. The system can monitor, detect, control, and access the network automatically in response to any type of signals which comes from related sensors. The smart system is design to be a simple, flexible and cost effective.

\section{ACKNOWLEDGEMENTS}

We thank the Department of Computer Science, College of Science, Mustansiriyah University, Baghdad, Iraq for thier support.

\section{REFERENCES}

[1] P.-S. Murvay and I. Silea, "A survey on gas leak detection and localization techniques," Journal of Loss Prevention in the Process Industries, vol. 25, pp. 966-973, 2012.

[2] M. Karami, G. V. McMorrow, and L. Wang, "Continuous monitoring of indoor environmental quality using an Arduino-based data acquisition system," Journal of Building Engineering, vol. 19, pp. 412-419, 2018.

[3] M. A. Ahmed, R. A. Hasan, A. H. Ali, and M. A. Mohammed, "The classification of the modern arabic poetry using machine learning," TELKOMNIKA Telecommunication Computing Electronics and Control, vol. 17, pp. 2667-2674, 2019.

[4] R. A. Hasan, M. A. Mohammed, Z. H. Salih, M. A. B. Ameedeen, N. Țăpuş, and M. N. Mohammed, "HSO: A Hybrid Swarm Optimization Algorithm for Reducing Energy Consumption in the Cloudlets," TELKOMNIKA Telecommunication Computing Electronics and Control, vol. 16, pp. 2144-2154, 2018.

[5] M. A. Mohammed, Z. H. Salih, N. Tăauş, and R. A. K. Hasan, "Security and accountability for sharing the data stored in the cloud," in 2016 15th RoEduNet Conference: Networking in Education and Research, 2016, pp. 1-5.

[6] M. A. Mohammed and N. ȚĂPUŞ, "A Novel Approach of Reducing Energy Consumption by Utilizing Enthalpy in Mobile Cloud Computing," Studies in Informatics and Control, vol. 26, pp. 425-434, 2017.

[7] D. S. Simbeye, "Gas Leakage Detection System (GLDS)," Tanzania Journal of Engineering and Technology, vol. 34, 2017.

[8] N. Q. Mohammed, M. S. Ahmed, M. A. Mohammed, O. A. Hammood, H. A. N. Alshara, and A. A. Kamil, "Comparative Analysis between Solar and Wind Turbine Energy Sources in IoT Based on Economical and Efficiency Considerations," in 2019 22nd International Conference on Control Systems and Computer Science (CSCS), 2019, pp. 448-452.

[9] M. A. Mohammed, R. A. Hasan, M. A. Ahmed, N. Tapus, M. A. Shanan, M. K. Khaleel, et al., "A Focal load balancer based algorithm for task assignment in cloud environment," in 2018 10th International Conference on Electronics, Computers and Artificial Intelligence (ECAI), pp. 1-4, 2018.

[10] M. A. Mohammed, I. A. Mohammed, R. A. Hasan, N. Ţăpuş, A. H. Ali, and O. A. Hammood, "Green Energy Sources: Issues and Challenges," in 2019 18th RoEduNet Conference: Networking in Education and Research (RoEduNet), pp. 1-8, 2019.

[11] Z. H. Salih, G. T. Hasan, and M. A. Mohammed, "Investigate and analyze the levels of electromagnetic radiations emitted from underground power cables extended in modern cities," in 2017 9th International Conference on Electronics, Computers and Artificial Intelligence (ECAI), 2017.

[12] O. A. Hammood, M. N. M. Kahar, W. A. Hammood, R. A. Hasan, M. A. Mohammed, A. A. Yoob, et al., "An effective transmit packet coding with trust-based relay nodes in VANETs," Bulletin of Electrical Engineering and Informatics, vol. 9, pp. 685-697, 2020.

[13] Z. H. Salih, G. T. Hasan, M. A. Mohammed, M. A. S. Klib, A. H. Ali, and R. A. Ibrahim, "Study the Effect of Integrating the Solar Energy Source on Stability of Electrical Distribution System," in 2019 22nd International Conference on Control Systems and Computer Science (CSCS), pp. 443-447, 2019.

[14] O. Hammood, M. N. Mohmad Kahar, M. Nafaa, and W. A. Hammood, "RESP: Relay Suitability-based Routing Protocol for Video Streaming in Vehicular Ad Hoc Networks," International Journal of Computers Communications \& Control, vol. 14, pp. 21-38, 02/14 2019. 
[15] O. A. Hammood, M. N. M. Kahar, and M. N. Mohammed, "Enhancement the video quality forwarding Using Receiver-Based Approach (URBA) in Vehicular Ad-Hoc Network," in 2017 International Conference on Radar, Antenna, Microwave, Electronics, and Telecommunications (ICRAMET), pp. 64-67, 2017.

[16] O. A. Hammood, M. N. M. Kahar, M. N. Mohammed, W. A. Hammood, and J. Sulaiman, "The VANET-Solution Approach for Data Packet Forwarding Improvement," Advanced Science Letters, vol. 24, pp. 7423-7427, 2018.

[17] L. Fraiwan, K. Lweesy, A. Bani-Salma, and N. Mani, "A wireless home safety gas leakage detection system," in 2011 1st Middle East Conference on Biomedical Engineering, pp. 11-14, 2011.

[18] S. N. Mahmood, A. J. Ishak, and S. T. Hussain, "GSM based gas leak monitoring system," Periodicals of Engineering and Natural Sciences, vol. 7, pp. 670-678, 2019.

[19] B. Azibek, S. Zhigerova, and M. S. Obaidat, "Smart and Efficient Health Home System," in Emerging Research in Data Engineering Systems and Computer Communications, ed: Springer, pp. 677-691, 2020.

[20] R. Zade, N. Khadgi, M. Kasbe, and T. Mujawar, "Online Garbage Monitoring System Using Arduino and LabVIEW," International Journal of Scientific Research in Network Security and Communication, vol. 6, pp. 5-9, 2018.

[21] A. Śpiewak and W. Sałabun, "A mobile gas detector with an Arduino microcontroller," Int J Computer Technol Appl, vol. 6, pp. 636-641, 2016.

[22] J. M. Wang and H. B. Wei, "Design of smart home management system based on GSM and Zigbee," in Advanced Materials Research, pp. 703-707, 2014.

[23] N. Mahzan, N. Enzai, N. Zin, and K. Noh, "Design of an Arduino-based home fire alarm system with GSM module," in Journal of Physics: Conference Series, p. 012079, 2018.

[24] J. N. Shehab, "Design and Implementation of Factory Security System," Journal of Engineering and Sustainable Development, vol. 22, pp. 162-171, 2018.

[25] S. Morris and W. Emmerich, "Object-oriented analysis and design," 1992. 